\title{
Getting Started: Publication Issues for Graduate Students, Postdoctoral Fellows, and Other Aspiring Addiction Scientists
}

\author{
Dominique Morisano, Erin L. Winstanley, \\ Neo Morojele and Thomas F. Babor
}

\section{Introduction}

In recent years, there has been increasing pressure on graduate and medical students, postdoctoral fellows, and even research assistants and lab technicians to write or co-author scientific publications. Some of this pressure has extended to undergraduates (e.g., Trammell, 2014), often before they have had the opportunity to take a statistics course.

The number of publication credits is frequently a key criterion for students' acceptance into advanced study, postdoctoral opportunities, and internship placements as well as for the receipt of scholarships, fellowships, grants, and employment. For novice academics, publication numbers and authorship order are often at the top of considerations for tenure-track advancement. More competitive universities that value high publication numbers might urge students and junior faculty to compose theoretical papers and review articles or to write reports based on publically sourced unpublished data (e.g., www.apa. $\mathrm{org} / \mathrm{research} / \mathrm{responsible/data-links.aspx)} \mathrm{instead} \mathrm{of} \mathrm{running} \mathrm{original} \mathrm{studies,}$ which take time and do not always yield publishable results. In some countries, students are advised to publish articles in addition to producing a monographstyle dissertation; in others, they are expected to focus solely on the production of a "compilation thesis" or article-based dissertation that might lead to

\section{How to cite this book chapter:}

Morisano, D, Winstanley, E L, Morojele, N, and Babor, T F. 2017. Getting Started:

Publication Issues for Graduate Students, Postdoctoral Fellows, and other Aspiring Addiction Scientists. In: Babor, T F, Stenius, K, Pates, R, Miovský, M, O’Reilly, J and Candon, P. (eds.) Publishing Addiction Science: A Guide for the Perplexed, Pp. 89-118. London: Ubiquity Press. DOI: https://doi.org/10.5334/bbd.e. License: CC-BY 4.0. 
multiple publications. Some students must produce dissertations that are based on published articles (possibly with multiple authors). In any case, for postgraduate trainees and junior academics, authorship is increasingly at the forefront of issues faced in education and early employment.

This chapter presents issues that are particularly relevant to publishing as a graduate student or postdoctoral fellow, but anyone early in her or his publishing career might benefit from reading through the topics covered. The chapter begins with a discussion of general issues related to authorship and then addresses the more specific topic of publishing graduate-level theses. The latter section focuses on the entire process of thesis publication, ranging from issues that might arise before writing one's thesis all the way to eventual postpublication submission to an appropriate journal. Our main sources of information on this topic come from North American and European universities in highincome countries, but the issues and solutions discussed are increasingly relevant to university students in other regions. Accordingly, special attention is provided to the challenges encountered by students or novice investigators in less resourced countries.

\section{General Issues}

The challenges of publishing early on the academic trajectory include making decisions about authorship and timetables, navigating ethical dilemmas, and balancing publication pressures with training goals. Yet publications can open doors for both career advancement and financial remuneration.

\section{Authorship}

As noted in Chapter 11, authorship of peer-reviewed journal articles is the "coin of the realm" in academic settings, although the ability to write even unpublished reports is a valuable skill in any work situation. For the great majority of graduate students and postdoctoral fellows, early-career authorship will come only from collaboration with faculty members, ${ }^{1}$ senior researchers, and supervisors. As such, both mentors and mentees should consider a number of ethical and practical issues that could arise on joint projects (see Chapters 14 and 15 for a discussion of authorship ethics). At the heart of such traineefaculty (or even employee-supervisor) collaborations lies an inherent power imbalance (Fine \& Kurdek, 1993; Gross et al., 2012). Often, the faculty members with whom students and trainees have the most interactions (and thus the greatest chance to do research) are responsible for providing them with recommendation letters and evaluating their work. These faculty members may even be responsible for trainee salaries, as in the case of graduate assistantships or postdoctoral fellowships. Many students and trainees begin with minimal 
experience and competence in publishing and must rely on faculty support and guidance. Even if students and postdoctoral trainees are consulted during the process of assigning authorship, faculty members generally make the ultimate decisions on where (or whether) students or trainees are placed on the author list. Students who disagree with or misunderstand such decisions might fail to voice their opinions for fear of negatively impacting the ways in which those faculty members will evaluate them.

The academic level of the collaborating faculty member or supervisor could also influence the authorship decision-making process. Senior faculty with established research grants might be more likely to give students or trainees opportunities for first authorship on co-authored publications. With potentially bigger labs or projects and greater numbers of volunteers and research assistants, senior faculty might even provide more chances to publish in general, handing over projects, ideas, and datasets to their mentees. In contrast, junior faculty members are frequently under significant pressure to get their own names on publications in order to earn research grants, advance to higher faculty positions, and gain tenure. As a result, they might have more concerns about sustaining and advancing their own careers than about taking time to help their students or trainees to publish.

Figure 5.1 provides a satirical view of authorship situations sometimes encountered by students who work on publications with more experienced or higher ranked investigators. Although the cartoon is a spoof, many academics would agree that it is uncomfortably close to the procedures witnessed in some research labs, centers, and departments. The procedures for determining student-faculty co-authorship are likely to vary by discipline, institution, and even culture, but they should ideally reflect a dynamic process that evolves as the authors revise and resubmit their article.

\section{THE AUTHOR LIST: GIVING CREDIT WHERE CREDIT IS DUE}

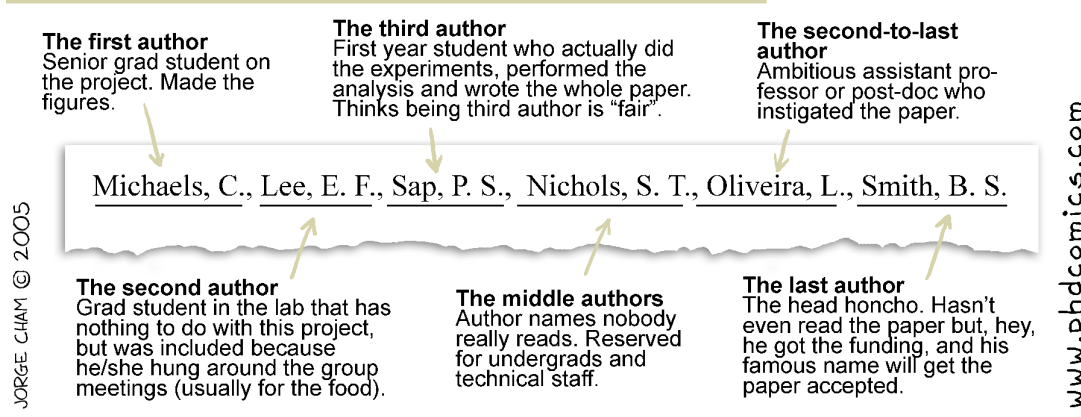

Figure 5.1: Authorship credit comic from "Piled Higher and Deeper" by Jorge Cham (www.phdcomics.com, reprinted with permission of author. All rights reserved.). 
Graduate students, postdoctoral fellows, and young professionals working in basic and applied research settings are often uninformed about acceptable procedures for deciding authorship within a given field or discipline. In addition, procedures seem to vary so greatly even within departments that it can be difficult to stay abreast of what constitutes acceptable practice. The availability of specific guidelines is indispensable to establish equal opportunities for student authorship and consistent procedures for student-faculty collaborations. As in the case of the more general issue of authorship (discussed above), there are specific guidelines available that can facilitate this process at some institutions and help prevent problems from arising in the first place. Some examples of these guidelines are discussed below. If they are not readily available at your research center or university, however, it is possible to adopt guidelines from another institution or professional society (see Chapter 11 for an example).

As a rule, graduate students should be the first authors of journal articles based on their thesis or dissertation manuscripts. Many disciplines and institutions enforce this broad principle. For example, the American Psychological Association's Ethical Principles of Psychologists and Code of Conduct (American Psychological Association, 2010) explicitly states, "Except under exceptional circumstances, a student is listed as principal author on any multiple-authored article that is substantially based on the student's doctoral dissertation" (Section 8.12). Further, the American Psychological Association indicates that faculty advisors should discuss publication credit with students as early as feasible and throughout the research and publication process. However, the "exceptional circumstances" mentioned highlight a universal gray area, and it is often the case that other factors might complicate seemingly straightforward authorship assignment, for instance when the graduate student's dissertation is based on part of an advisor's grant.

In line with changing times, several institutions of higher learning have posted general authorship guidelines on their websites. The University of Pennsylvania, for example, has developed a broad policy on fairness regarding authorship credit for publications co-authored by graduate students and faculty. A university-wide process for determining authorship sets forth simple principles and an appeal process and requires graduate programs to provide more specific guidelines to reflect interdisciplinary and interdepartmental differences in assigning authorship credit (University of Pennsylvania's Office of the Provost, 2013). Mandating such procedures within each graduate group clarifies expectations about authorship for both students and faculty members. Specific departmental guidelines cover topics such as authorship criteria (specific and general principles regarding the kind of work that warranted a publication credit), whom to consult to resolve disputes, and the issues that faculty should discuss with students when beginning joint projects. Examples of such issues include (a) whether the graduate student will share authorship credit, (b) the expected order of authorship, (c) the division of labor on the project, and (d) when to revisit or review work that is being completed by each 
collaborating member of the pair or group. The University of Alberta's website hosts a similar set of guidelines around intellectual property and authorship (University of Alberta, 1996).

In general, with the expansion of the Internet as the primary tool of communication in most circles of higher education, online policies appear to be an efficient and user-friendly way of spreading authorship and intellectualproperty guidelines to junior investigators with adequate access. Harvard Medical School Office for Research Issues (1999), the University of Toronto (2007), Washington University in St. Louis (2009), and the University of Cambridge (2014), among others, have also provided statements on authorship or intellectual property for members of their institutions-although some are rather brief in nature, they seem to be evolving. University of Pennsylvania and University of Alberta guidelines provide the best models for the development of similar policies in higher learning institutes across the world. Such university-wide policies are an excellent way to keep students, postdoctoral fellows, and faculty members informed about the most fair and equitable procedures to follow in joint-authorship situations.

In what has become a US benchmark article for writings on student-faculty co-authorship, Fine and Kurdek (1993) produced a set of authorship guidelines based on the idea that both faculty and students should meaningfully participate in the authorship decision-making process. Fine and Kurdek recommended that, at the very initiation of joint projects, supervisors and faculty collaborators provide new students and postdoctoral fellows with information about how authorship decisions are made. They also put forth a series of specific and potentially controversial recommendations about student authorship, arguing, for example, that supervisors cannot and should not expect as much from students as from experienced professional colleagues. Instead, the authors suggested that there should be a different standard for the level of professional contribution required by students to attain a given level of authorship credit within a student-faculty collaboration. At the same time, however, they maintained that student contributions must be professional in nature: that is, creative, intellectual, and integral to completion of the paper. Examples of such contributions might include developing the research design, writing sections of the manuscript, integrating diverse theoretical perspectives, developing new conceptual models, designing assessments, contributing to data-analysis decisions, and interpreting results. Other tasks - such as entering data, carrying out statistical analyses specified by the supervisor, and typing a manuscript-might warrant a footnoted acknowledgement, but they would not, according to the authors, deserve authorship credit. Fine and Kurdek suggested that supervisors and students decide early in the publication process what combinations of professional activities would merit a given level of authorship credit for both parties. These decisions might now need to be checked against journal or discipline-specific guidelines and standards, many of which have become more detailed over the years in response to authorship confusion and transgressions (see Chapter 11). 
Fine and Kurdek (1993) raised a variety of issues and case scenarios surrounding authorship in student-faculty collaborations that are still relevant more than two decades later. Chapter 11 is a direct response to articles such as this as well as to the diverse but brief and scattered array of individual university guidelines mentioned above. Students, postdoctoral fellows, and other early investigators in the process of article publication should refer often to the general set of very practical authorship guidelines provided in Chapter 11 . These guidelines span the planning, drafting, and finalization stages of authorship. Indeed, the chapter is an ideal source for beginning researchers to consult as they try to determine where (or if) they should appear within author lists. It touches on potentially controversial issues, such as what constitutes a "substantive" authorship contribution. For example, if a graduate student has developed, coordinated, and carried out a research project for a mentor or supervisor but did not come up with the original idea, analyze or interpret the resulting data, or participate in the writing of the ensuing manuscript, does he or she deserve to be listed as an author on publications arising from the project? According to the recommendations in Chapter 11, the answer is no, because there is no involvement in the writing process (and to be an author, one must write!). However, one might argue that this student should at least be given the option of contributing in a more substantive way to the publication process in order to earn authorship. Students might therefore want to explicitly express their interest in being involved in future publications.

In summary, there is a great amount of room for improvement in the realm of early-career publishing. The process has not yet been clearly documented in terms of student and junior investigator rights, responsibilities, and roles. Although progress has been made in clarifying the issues and formalizing some long overdue policies, much remains to be done at both the level of the academic institution and the level of the individual faculty and trainee. Fortunately, there are plenty of opportunities to learn more about this area to improve the process. The mentorship of a seasoned investigator can provide her or his students, postdoctoral fellows, or other trainees with a golden opportunity to ascertain how publication works. At the very least, the sharing of articles such as this chapter might help to raise awareness of the issues and how to deal with them.

\section{Publishing One's Thesis or Dissertation}

Converting the thesis or dissertation into one or more journal articles is a key publishing opportunity for aspiring researchers. Incentives to early publication include building confidence, establishing a pattern of scholarly activity, enhancing student satisfaction, increasing knowledge of the publication process, and advancing or updating the science. ${ }^{2}$ Sometimes, early publication affords a novice researcher the opportunity to demonstrate the need for a particular area of research (Robinson \& Dracup, 2008). As noted above, there are 
many incentives to begin publishing early or publishing before the research data "shelf life" has expired, particularly for those who are interested in academic careers (Resta et al., 2010). Given the amount of work that is invested in the preparation of a thesis or dissertation, this is often the ideal place to begin one's publication career, and it is important to be strategic about the development of a publication plan.

When considering a timeline for publication, there are several questions researchers might ask themselves. For instance, "What is my academic trajectory?" Or, "How fast is this area of research developing?" "How much information is available in my content area?" "Is the literature up to date or does it need updating?" "What is the potential real-world impact of my research?" "Does current literature support the need for my research, or do I need to build a published case?" "What audience is most interested in my area of research?" Answering these simple questions could help a novice researcher to develop a successful publication plan both during and after thesis or dissertation completion. The following section describes additional considerations.

\section{Before Writing One's Dissertation: Format Considerations}

There are several different doctoral dissertation formats, which vary in acceptability depending on the country and the university in which they are written. Two of the more popular formats are the monograph style (single authored) and the separate manuscript style (multiauthored; Hagen, 2010). Many graduate programs increasingly favor dissertations that depart from the traditional monograph style and that instead facilitate the incremental translation of the dissertation into publishable manuscripts.

The manuscript style of dissertation-although it might have different names-generally requires that chapters be written in article format. For example, at The Johns Hopkins Bloomberg School of Public Health, a student can choose to write a traditional monograph-style (chapter-based) dissertation or a "papers option." The latter format requires that a minimum of three of the dissertation chapters take the shape of publishable manuscripts, with one chapter usually serving as a critical review of the literature and two chapters comprising empirical analyses. To the extent that the papers are "publishable," whether they must be submitted or accepted for publication to earn a degree varies across universities. In the Nordic countries (Denmark, Iceland, Finland, Norway, Sweden), most of the dissertation articles must have been published or accepted for publication before the dissertation can be passed.

Manuscripts may represent the entire chapter or a portion of a dissertation chapter that is supplemented with a synthesis or independent introduction. An example of the purposive changes that may be made to a manuscript to fulfill the chapter requirements include the addition of regional data and epidemiological information, the definition of terms for lay readers, a longer and more 
in-depth explanation of the phenomenon, the theoretical tenets guiding the proposed study, and a conclusion that illustrates student mastery of the subject.

The extent to which manuscripts need to be interrelated and reflect a single focus of research, as occurs in a monograph-style dissertation, varies across institutions, departments, and advisors. It is, in part, contingent on the clarity of the institutional guidelines provided. Anecdotal evidence suggests that the rules are not concrete. Furthermore, if one is writing a literature-review chapter, it is helpful to keep in mind that many addiction journals do not accept unsolicited review articles and that getting this type of manuscript published could be a special challenge. Literature reviews using a systematic or structured approach are more likely to be published.

If one has the opportunity to choose which dissertation format to take, it is important to consider the benefits and particular challenges of a style that is meant to facilitate the publication process. For example, even if one chooses to write one's thesis in the manuscript style, resulting chapters might still require significant revision if they need to be shortened and formatted later for a particular journal and written with a broader audience in mind than one's dissertation committee (Azar, 2006).

\section{In the Trenches: Writing One's Dissertation with Publication in Mind}

While writing the thesis or dissertation, it is helpful to think about whether chapters or sections will eventually be suitable for journal publication. If the answer is yes, then several issues arise that should be addressed sooner rather than later. For instance, if one hopes to publish one's data in a particular journal, it is important to consider the author guidelines during the drafting stage in order to tailor the writing and formatting style of the dissertation toward specific journal requirements. It is also useful to consider the intended audience of that journal early on (see Chapter 3 for issues related to choosing a journal). Even if a particular target journal has not yet been identified, the chapter can be written with the potential audience in mind (e.g., clinicians or policy makers), in a way that can help refine the scope of the manuscript. It is also important to remember that if one publishes data or other study-related material before submitting the dissertation or thesis, one must consider which parts of the published manuscript(s) are eligible for inclusion in the final dissertation. Journals and publishers will often grant permission to students to submit published manuscripts as dissertation chapters, but it is wise to request written confirmation.

Furthermore, for many, a considerable amount of time can elapse between creating initial drafts of the thesis or dissertation and preparing to publish the content in a journal. It is therefore important to maintain adequate documentation of all analyses and datasets. The lengthy dissertation-writing process plus the journal-submission process could result in a situation in which, months 
or years after data collection, a journal reviewer requests that data analyses be revised or substantially expanded. Although this issue is generally relevant for the authors of any research study, the significant time that it takes to complete the dissertation amplifies the importance of keeping an adequate record of completed work.

In sum, the forward-thinking student will strategically balance dissertation requirements with potential journal submission requirements. This is not always easy. Dissertations typically require a much greater level of detail than most journal manuscripts. This means that significant portions of the dissertation will need to be cut, edited, and fine-tuned for publication. Writing style might also need adjustment, depending on the intended audience (e.g., dissertation committee vs. journal editors, and reviewers vs. the scientific community at large). There are benefits to this conversion exercise, however. The process of transforming dissertations into publishable articles teaches graduate students not only how to summarize research findings in a succinct manner, but also how to communicate to a broader audience than faculty and committee members.

In the long and sometimes dark days of creating one's dissertation with publication in mind, it is key to remember that publication presents multiple rewards. In addition to fulfilling degree requirements and contributing to scientific advancement, all of one's hard work can be directly applied to making progress on the career front. Publication is, after all, the coin of the realm.

\section{Preparing for Publication}

Once the dissertation has been approved, and the appropriate celebrations have concluded, the time for publication is nigh. ${ }^{3}$ Frequently, suggestions made during the final dissertation defense will be relevant to the initial stages of preparing for publication. During this phase, several issues inevitably will come to the surface.

The first is authorship. As previously discussed, the student should be the first author the majority of the time. In the case of multiple authors, institutional and disciplinary guidelines or even our own recommendations (see Chapter 11) can help to determine authorship order. If committee members are to be invited as potential co-authors, it should be made clear that all authors are required to have made substantial contributions to the journal manuscript itself, as opposed to simply "being a part" of the dissertation-development conversation. Given that many journals now require written statements that specify authorship contributions, this is no longer just a traditional courtesy.

Assignment of authorship is a dynamic process that will depend on the amount of time that has lapsed since graduation, the extent of revisions required for publication, and the context in which those revisions are made. For example, revisions are sometimes required at the final stage of the dissertation-approval 
process, and it might not be feasible to anticipate the target journal until after graduation. If substantial revisions are requested, the opportunity might arise to seek expertise outside of the dissertation committee. The recruitment of external co-authors can offer several advantages. First, fresh insight might facilitate the process of tailoring a manuscript for a particular target audience. Alternatively, external experts might be able to address weaknesses in a manuscript that fall outside the student's field of knowledge. Sometimes new graduates might recruit the co-authorship assistance of a former labmate or graduate-student peer to make broad cuts in superfluous content that might be difficult for the primary author to do. This offers the added opportunity or benefit of publication experience for a peer.

One should also consider publication of the dissertation itself, with or without an accompanying short-form article. This is a requirement at many European institutions, where dissertations often result in published books. Some graduate programs might provide structured guidance regarding the process of indexing the dissertation, copyrighting dissertation materials, and publishing the dissertation as a complete document. Some university libraries now do this automatically (e.g., McGill University: www.mcgill.ca/library/find/theses). Alternatively, there are an increasing number of low-cost opportunities to publish one's full work online. A sampling of websites offering this possibility is presented in Box 5.1. For example, Dissertation Abstracts Online indexes dissertation abstracts and disseminates them across a wide range of literature search engines. ProQuest Dissertations and Theses allows graduates the option to purchase a permanent link for dissertation abstracts; this can be useful for citation purposes. Other sites offer interested readers the choice to either download or receive a .pdf or paper copy of a dissertation for a nominal fee.

If one is looking to reach the widest audience, writing the dissertation in manuscript style can facilitate the process of achieving one or more first-author publications. Finding the time for even one article can be difficult after graduation, when important life changes (e.g., finding or starting a new job, starting a family, catching up on things that might have been on hold during graduate school) are often inevitably competing for one's time. This is why a postdoctoral position, when available, offers an ideal solution: the very nature of the job often includes the development of publications as a primary goal. Furthermore, depending on the area of research, postdoctoral positions of 1-3 years might not allow sufficient time to be a part of a new project from inception to publication. Entering the position with one's own dissertation provides an immediate publishing goal.

\section{Publication Timelines}

Some supervisors and faculty members feel it is important to set formal limits, policies, and procedures regarding the time that students have to publish their 
1. UMI (University Microfilms International) Dissertation Publishing: www.proquest.com/products-services/dissertations

a. ProQuest Dissertations \& Theses Global database

b. American Doctoral Dissertations

c. Masters Abstracts International

d. ProQuest Dissertations and Theses-United Kingdom (UK) \& Ireland

e. Dissertations \& Theses @

f. Dissertation Abstracts International/Dissertation Abstracts Online/Comprehensive Dissertation Index

2. OCLC WorldCat Dissertations and Theses (includes manuscripts from OCLC member libraries): http://www.oclc.org

3. Networked Digital Library of Theses and Dissertations: www. ndltd.org

4. DART-Europe (28 countries): www.dart-europe.eu/basic-search. php

5. BNF: Thèses et écrits académiques (France): http://signets.bnf. $\mathrm{fr} / \mathrm{html} /$ categories/c_011theses.html

6. EThOS (UK): http://ethos.bl.uk

7. theses.fr (France): www.theses.fr

8. Theses Canada Portal (Canada): www.bac-lac.gc.ca/eng/services/ theses/Pages/theses-canada.aspx

9. DissOnline (Germany): www.dnb.de/DE/Wir/Kooperation/ dissonline/dissonline_node.html

10. Tesionline (Italy): www.tesionline.com/intl/index.jsp

11. Tesis doctorales: TESEO (Spain): www.educacion.es/teseo

12. dissertations.se (Sweden): www.dissertations.se

13. Database of African Theses and Dissertations (Africa): www.aau. org/page/database-african-theses-and-dissertations-datad

14. Networked European Deposit Library (France, Norway, Finland, Germany, Portugal, Switzerland, Italy, and the Netherlands): www.ifs.tuwien.ac.at/ aola/publications/thesis-ando/NEDLIB. html

15. Google Scholar: http://scholar.google.com

16. Amicus (Canada): http://amicus.collectionscanada.ca/aaweb/ aalogine.htm

Box 5.1: Online dissertation indexing and publishing resources. 
thesis or project data in a scholarly journal. When this timeline is expired, there might be a debate over whether the right to publish the data should be forfeited to the supervisor or members of the dissertation committee. It is a common belief that if work is not published in a timely manner, it is unlikely to be published at all (Rudestam \& Newton, 1992).

In most cases, students should have the right to publish their results as first author, even with considerable delays. If the timely dissemination of important scientific findings is at the root of such policies, however, then these procedures might be warranted. Graduate students sometimes lose interest in publishing project data after their theses have been defended (or even before!), and important or interesting scientific results are often buried under more salient tasks at hand (e.g., seeking full-time employment). Regarding specific policies, this is something that supervisors and dissertation committee members should discuss with their students early in the collaboration process. A reasonable solution for the various parties in these cases might be to designate a mutually agreeable time period together and then sign a written agreement that would bind them to it.

One example of an individual professor's policy that was put together and published online is that of Professor Karl Wuensch $\left(2008,{ }^{4}\right.$ East Carolina University). On his website, Wuensch clearly states his policy regarding timeliness of publication for student theses. For example, if the thesis is the student's idea, the student does most of the work (e.g., collects and analyzes the data, writes the manuscript), and the manuscript is prepared within 18 months from the date of the research initiation or one year from the date of the thesis defense, then the student is first author. If warranted by their contributions to the journal manuscript, the thesis director and other committee members might also be listed as authors. However, if the student does not complete the research, including defending and depositing the thesis and preparing the manuscript for submission for publication within the time limits mentioned above, then all rights to use that thesis data revert to the thesis-committee director. Wuensch also indicates procedures for other situations that might arise, for example, if the student-submitted manuscript is not accepted upon initial submission to a journal. Guidelines such as these might also be adapted for postdoctoral fellowship projects.

In the discussion of publication timelines, it is important to remember that exceptions (e.g., illness) can always be considered if one fails to publish within the agreed-upon period-one need not despair. As long as steady progress is shown and good communication among co-authors is in place, the pressure that might come from thesis advisor(s), co-authors, and committee members can be reduced. Sometimes the issue lies not with one's own progress but with getting co-authors to respond in a reasonable amount of time. Although all authors might struggle with the multiple-author publication process, novice writers in particular must learn to develop effective communication strategies, ideally from their advisors. It can be useful to set specific time frames for 
co-authors with concrete deadlines and frequent email reminders. If response time becomes unreasonable, a direct conversation with these co-authors about their place on the manuscript might become necessary. If motivation or writer's block is an issue, it might be useful to take advantage of some of the strategies presented in Box 5.2.

\section{Publication Contracts and Guidelines}

Several attempts have been made to develop formal procedures to address the ethical, practical and logistical issues discussed above. Professor Bruce M. Shore, an educational psychologist and professor emeritus at McGill University (Montreal, Canada), developed a formal supervision contract (Shore, 2014) for use with students. This contract covers matters such as authorship order, publication credit, and general responsibilities of both the advisor and the student within the supervisee-supervisor relationship. As a supervisor, he required that all of his students read, discuss, and sign the contract before agreeing to work with him, and he often raised the issues involved with authorship before projects even germinated. He agreed to share his contract as an example of an advisee-advisor agreement for the purposes of this chapter (see Appendix A). The process recommended in the agreement is refreshing. Regardless of whether a student agrees with the various conditions of the contract, the issues are transparent and open to discussion at the onset of the mentee-mentor relationship.

A similar guideline was developed by graduate students at the University of Connecticut School of Medicine (Cornell et al., 2014; Authorship Rights of Graduate Students, see Appendix B) to protect graduate students working in various areas of health science by clearly defining student-faculty authorship criteria and the ethical responsibilities of each party. The procedures described in the guideline (as well as Professor Shore's contract) can be adopted by department chairs, center directors, student organizations, and individuals to protect graduate students from negligence or mistreatment related to scientific authorship.

\section{Financial Remuneration}

Conversations about financial remuneration can arise in the creation of a manuscript. Some faculty and supervisors feel that students or other individuals who are paid as research or graduate assistants should not be given authorship because credit for performed work is being given in the form of a salary. These same faculty members might express that publication credit replaces the need for financial remuneration, because the individuals will ultimately benefit from having their names listed on a paper. Fine and Kurdek (1993) are firm in their position that paying a research assistant or graduate student should not 
Even if you love writing, sometimes it takes great effort to put a line down on paper. With an infinite array of potential distractions on the Internet (e.g., social media), especially when one must make use of online resources (e.g., Google Scholar, PubMed) to write, writing time can suffer. Add to that the existence of smartphone apps and offline "distractions" (e.g., work tasks with deadlines, that new novel you can't put down, television, family or household obligations, social invitations), and finding time to write can be nearly impossible. Some potential solutions:

1. Make a writing schedule and stick to it. Mark the time in your calendar, and treat it like you are getting paid by the hour. If an extra incentive is needed, take a cue from behavior-modification experts and give yourself a small reward when you successfully follow through with your writing goals for the day (or even the hour!).

2. Find a great place to write. Many new scholars find that writing at a local cafe or public library is easier than writing at home. Alternatively, designating an area of your home for "writing" might help to keep you on task.

3. Do something about your smartphone/tablet while you write. Put it on "airplane" mode; take it offline; or, at the very least, turn off notifications.

4. Take advantage of free, online writing tools and apps. Do a quick web search for "free writing tools," and you will encounter a bevy of computer- and smartphone-based applications that will allow you to do such things as (a) keep you offline (e.g., "Freedom" app), (b) block you from specific sites (e.g., "Self-control" app), (c) organize your thoughts (e.g., "Evernote" app), (d) monitor writing breaks (e.g., "Time Out" app), or (e) be rewarded or "punished" for progress (e.g., "Write or Die" app). The popular website The Huffington Post has even designated an entire section of their site for keeping up to date with the latest writing apps: www.huffingtonpost.com/news/writing-apps. For those without computer access, setting frequent, proximal, and challenging yet achievable short-term goals has been closely linked to achievement success (see Morisano, 2013).

5. Give yourself a few minutes each day to de-stress. Often, our most creative ideas arise when we pull ourselves out of "go mode" and take a moment to sit and think, relax, take a walk, close our eyes, exercise, or meditate (e.g., with Jon Kabat-Zinn at www.youtube. com/watch?v=iZIjDtHUsR0). 
6. Keep up-to-date on the latest research by subscribing to relevant listservs such as the one maintained by the Kettil Bruun Society for Social and Epidemiological Research on Alcohol (instructions at www.kettilbruun.org/Listserve.htm). They are often the source of good ideas and occasionally an inspiration for future articles.

Box 5.2: Writing strategies.

substitute for authorship credit, when credit for professional and intellectual contributions is due. ${ }^{5}$ This extends to the hiring of consultants to contribute to the research and writing of an article; payment is not a substitute for authorship. The extent of controversy surrounding financial remuneration indicates that this topic should be covered when creating institutional and departmental guidelines surrounding authorship procedures. In light of the authorship criteria discussed elsewhere in this chapter and in Chapter 11, it is clear that neither financial reimbursement nor its absence should be considered in the determination of authorship credits.

\section{The Nitty Gritty: Submitting a Manuscript and Responding to the First Rejection}

After carefully choosing a target journal (see Chapter 3 for advice), one should normally write a cover letter to the journal's editor and a brief description of the manuscript. Some journal editors might have sympathy for novice writers when sending written feedback (e.g., by providing more detail), so one's inexperience could be worth noting here. One should be mindful that some journals require specific cover-letter content (e.g., word count, conflict-of-interest statement); therefore, author guidelines must be consulted in advance. These are most often found under Author Guidelines or Instructions for Authors on journal websites, or in the paper copy of the journal itself. Some journal editors (particularly of smaller journals) are also open to receiving presubmission emails to gauge interest in potential submissions; this is worth considering.

Even for the most fastidious researchers and stellar writers, the day will likely arrive when a rejection letter is received. If the rejected work is based on one's dissertation data, the decision can be particularly devastating, given the time and energy invested (and other issues previously discussed). It is important to understand that rejection is simply a part of the writing and publication process-even senior and experienced researchers have manuscripts rejected. ${ }^{6}$ It is surprisingly easy to forget that if one is reaching for the stars and submitting to a competitive 
journal, acceptance rates are low. Even lower ranked journals are increasingly incorporating rigorous standards that might require a decent paper to go through a "revise and resubmit" round or two before acceptance. The most productive step to take post-rejection is to read and incorporate reviewer feedback as much as possible into a new draft, and try, try again (at another journal, unless resubmission is specifically invited). Chapter 12 provides guidance on how to respond to editors' requests for revised manuscripts.

\section{A Word on Predatory Publishers}

With the dramatic expansion of open-access and online journals (see Chapter 3), a number of for-profit enterprises have created new "journals" that will publish almost any article submitted for a processing fee ranging from \$500 to several thousand dollars (Beall, 2012). The name "predatory publisher" has been applied to this type of business because it involves charging publication fees to authors without providing the editorial and publishing services associated with legitimate journals. Several new addiction-science journals have been launched by these publishers, raising serious questions about their impact on a field that is already plagued by conflict-of-interest threats from the alcohol, tobacco, gambling, and pharmaceutical industries (see Chapter 16).

The characteristics of these journals include rapid acceptance of articles with little or no peer review; aggressive marketing, often using poor grammar and syntax; journal editors with no academic standing in the addiction field; misleading or nonexistent publication metrics (e.g., impact factors, indexing services); and publication fees that are not revealed until after the article is accepted.

It is easy to understand both the frustration of a new investigator who might receive multiple rejection letters and the appeal of an online journal that levies page charges after a cursory review. If early-career scientists or trainees choose to publish in such journals, however, the most likely consequence is to appear to peers, grant reviewers, potential employers, and promotion committees to be naive, unethical, or desperate for authorship credits. Many researchers are not familiar with the complicated and often confusing developments in journal publishing and may be easily scammed and embarrassed. Fortunately, resources on how to protect the integrity of science and avoid these unscrupulous phantom publishing operations masquerading as addiction journals are available, including Jeffrey Beall's (2015) list of predatory publishers (see References for a link). Prospective authors should also consult Chapter 3 of this book and the updated website of the International Society of Addiction Journal Editors (ISAJE; www.isaje.net), which provide a list of journals that subscribe to the Farmington Consensus, a code of ethics for journals and journal editors (Farmington Consensus, 1997). 


\section{Special Issues of Relevance to Students and Junior Investigators from Low- and Middle-income Countries}

Thus far, this chapter has focused on publication issues that are likely to be most relevant to those from well-resourced countries with an established scientific community in the addiction field. Students and junior investigators in less resourced countries face a number of different issues related to conducting and disseminating research (see Chapter 4 for a discussion of broader issues related to addiction research in developing countries). The following section addresses some of the special challenges encountered by students and novice addiction researchers from low- and middle-income countries (LMICs) as well as those from LMICs who earn their degrees from universities in developed countries and then return home. There is an imperative at both the national and international levels to publish research on addiction issues that is relevant to populations outside of Europe, Australia, and North America. High-quality dissertation research in general has the potential to significantly impact addiction science. Further, individuals from LMICs have especially strong obligations (and pressures) to conduct research and publish the results. In many LMICs, research is used to shape both the policy agenda and prevention/intervention programs. But most of the evidence on what policies and interventions "work" to reduce substance-related harms is based on studies conducted in developed countries. Indeed, the notion that research is limited in LMICs is highlighted by the shocking 10/90 gap statistic, according to which, only $10 \%$ of global research spending is directed to health problems that comprise $90 \%$ of the world's disease burden (Global Forum for Health Research, 2004).

\section{General Capacity Challenges}

The capacity of individuals to conduct and publish research varies considerably within and across LMIC academic institutions. In many university environments, salaries may be low, with both high teaching loads and competing demands. Personal financial constraints might compel academics to undertake other activities, such as seeing private patients or conducting various types of consulting work to supplement their incomes. Academics in LMICs often have minimal staff support and must conduct the bulk of their research work unassisted. In better resourced environments, investigators are more likely to have staff assistance for many of the activities that are required to write and submit papers for publication (e.g., literature reviews, data collection, entry, and data analysis) and for other aspects of research (including grant writing).

Publishing in countries with minimal research infrastructure outside of an academic institution is a special challenge, because writing is often lower on the priority list than tasks that are directly related to conducting the research, 
running prevention and intervention programs, or moving on to the next project. The final product of research is often a report for a local or national agency rather than a formal journal article. Although reports are an important mechanism for disseminating research findings, redrafting them into journal articles is necessary for the data to reach a broader scientific audience, to influence work in other LMICs, and to contribute to global knowledge. Publishing in a peer-reviewed outlet might also provide the author(s) with helpful feedback and ways to improve the work and thus the contribution.

Converting reports into journal articles under intensive work constraints can be a difficult, albeit surmountable, challenge. ISAJE has developed a writing mentorship program for this purpose (see http://www.parint.org/mentor_1. htm for more information; Miller, 2011). It provides novice researchers with the opportunity to be mentored by senior researchers, which can be useful if the immediate work environment does not provide sufficient opportunities to learn how to write for peer-reviewed academic journals.

Some LMIC researchers might sometimes fear that their work does not meet the standards of certain journals. With the development and use of increasingly sophisticated equipment and statistical techniques in high-income countries, the perception might arise that any research that is not state-of-the-art is not publishable. This is absolutely not the case. As suggested in Chapter 4, LMIC research may provide drug and alcohol policymakers with regionally specific data and evidence-based interventions. When implementing new laws, treatment policies, or programs anywhere, it is imperative that they are culturally appropriate and relevant. Furthermore, it is useful for researchers in Europe, Australia, and North America to have a more global perspective on research and prevention or intervention outcomes when developing their own protocols and policies. Exposing addiction scientists from non-LMICs to researchers from LMICs might lead to important investigative collaborations and cross-cultural research. Some of the most valuable studies of alcohol and drug screening, brief intervention, treatment, and epidemiology were conducted as cross-national collaborations between researchers from LMICs and highincome countries (Humeniuk et al., 2012; Rehm et al., 2010; Saunders et al., 1993). By regularly reading journal articles, attending conferences, and joining international research societies, LMIC researchers can gain exposure to diverse international research and build the confidence, skills, and connections that could lead to opportunities for international collaborative research.

\section{Research Topics}

Although there is still a significant underrepresentation of LMIC publications in scientific journals, improvements have been observed in recent years (Large et al., 2010; Warner et al., 2014). Large and colleagues demonstrated that the proportion of psychiatric publications from LMICs, as identified via PubMed, 
increased from $8.0 \%$ in $1998-2002$ to $12.5 \%$ in $2003-2007$. Similarly, Warner and others reported an increase in LMIC research publications in a leading addiction journal (Tobacco Control), from $10.1 \%$ in $1992-2006$ to $30.9 \%$ in 2007-2011.

The relative lack of studies emerging from many developing countries in a multitude of research areas, however, provides ample topics for publication. Recent graduates have an easy publication target: their dissertations or theses. Academics will likely conduct new research. Further, people in government agencies, clinical settings, and nongovernmental organizations, who may not have access to original data, might consider alternative publication routes such as narrative or systematic reviews that involve synthesizing the results of multiple research studies on a specific subject. The Cochrane Collaboration site (www.cochrane.org) can be consulted for information on potential review topics and systematic-review writing procedures. Similarly, it is possible to write case studies, letters, or policy and opinion pieces, all of which can stimulate public debate and influence policies.

\section{Selecting an Appropriate Journal}

As indicated in previous chapters (e.g., Chapter 3), there are many addiction journals, but the selection of the "right" journal can present special challenges for those from LMICs. A number of competing considerations might influence the choice.

First, in both developed and developing countries, many academics are under pressure to publish in "high-impact" peer-reviewed journals (see Chapter 3 for a discussion of impact factors). In South Africa, for example, academic institutions receive government subsidies based on the number of peer-reviewed publications produced in journals that have been accredited by the Department of Higher Education and Training. Moreover, in many LMIC institutions, the academic evaluation of faculty and their potential for career advancement is dependent on their publication record.

Second, authors might be faced with having to choose between publishing in a high-impact international journal that furthers their research careers or publishing in a low-impact local journal that reaches the public health audience of interest. In some cases, a middle-ground solution can be reached (e.g., publishing one's papers in both types of journals under agreed-upon conditions; see Chapters 3 and 4 for a discussion).

Third, the topical foci or missions of different journals must also influence one's choice. Some journal reviewers and editors might not have an interest in studies of non-American or non-European populations. Advance familiarization with the contents of the journal under consideration can help to gauge the likelihood that an LMIC health or addiction issue would engage the journal's editors and readership. 
Finally, one could consider publishing in an open-access journal, which is usually accompanied by payment (although it is important to take heed of the predatory publishers previously mentioned!). Advantages to authors might include increased accessibility and citations, which contribute to researchers' rankings and assessments. However, submission or publication costs can be high and difficult to justify in the case of limited research funds.

\section{Language}

Many times a manuscript is rejected by a journal not because of the quality of the research but because of the authors' failure to express their ideas clearly. For authors whose first language is not English, translating one's work for Englishlanguage journals can be difficult. Writing in English can even be a challenge for individuals who have attended English-language academic institutions and who have written their theses or dissertations in English. Converting the dissertation or thesis to the shortened format required for most journals can add to the difficulties of working in a second or third language and can lengthen the time to publication. To manage such language constraints, it is advisable to invite a native English speaker to serve as a co-author and help with editing, as long as she or he meets all the key authorship criteria. International conferences and meetings can be a good forum for networking with potential co-authors. Alternatively, authors may consider using English-language editing services, which usually entail a fee (e.g., http://webshop.elsevier.com/languageservices/ languageediting, http://wileyeditingservices.com/en/english-language-editing).

\section{Access to Literature and the Internet}

In numerous academic and other institutions in LMICs, access to journal articles, books, and other relevant literature is a major challenge that hinders research, writing, and publishing. Paper copies of articles and other literature often have to be ordered via slow, costly, and unreliable interlibrary loan systems. Furthermore, many academics do not have easy access to online journals because (a) they have unreliable Internet connections, (b) their institutions do not own subscriptions to the required journals, or (c) they might be unaware of free or reduced-cost options for accessing journal articles. In 2002, the World Health Organization and number of major publishers established the Health Inter-Network Access to Research Initiative (HINARI) to directly address such difficulties. HINARI provides free or reduced-cost online-journal access to health workers and researchers from local, not-for-profit institutions in many LMICs. More information about the initiative, including eligible countries, instructions for access, and related initiatives is available on the HINARI website (www.who.int/hinari/en). 
The lack of consistent and reliable Internet access also causes problems at the online article-submission stage for authors from LMICs. This process can be lengthy even for those with good Internet connections. Establishing collaborations with researchers who have better access to these resources might, in some cases, help to address this challenge.

\section{Challenges of Rejection}

As noted above, it is quite common for manuscripts to be rejected for publication after initial submission. Papers from non-European and non-North American settings are sometimes rejected because the reviewers or editors are not aware of the significance of the research in its cultural or local context. In such cases, authors may exercise their right to appeal the rejection if they believe it is based on the editors' or reviewers' lack of appreciation of the importance of the topic. It might also be useful to precede submission with an email to the journal editor about the topic and its importance before sending it in.

\section{Comment: Be Optimistic}

Despite the significant challenges for novice scientists from LMICs, there are advantages to the relative lack of existing research for those just setting out on their research and publication careers. One might be able to claim truthfully that the research has never been conducted or replicated outside of the developed world. Furthermore, the presence of numerous academics from LMICs who continue to be prolific despite the under-resourced settings in which they work provides evidence that many of the aforementioned difficulties are surmountable.

\section{Conclusions: Take the Long View}

A career in addiction science is not for everyone, but it can be very rewarding for those who have the motivation and the aptitude (Edwards, 2002). The best way to begin is to attempt publication of one's thesis or dissertation, work closely with one or more well-published investigators, employ the writing strategies discussed, and find a place for postdoctoral research or clinical training. The writing process from student to postdoctoral fellow to junior researcher is generally the same, although the level of autonomy increases with each transition. Greater autonomy is usually accompanied by more security regarding one's place in the publication process and an increased ease in negotiating authorship order. Further, full-time research scientists are not the only ones who enjoy the rewards of publishing. Those who work in clinical settings, government agencies, and other organizations often find that while journal 
publications are not rewarded by their employers, neither are they likely to be discouraged. The pros of publishing one's work usually outweigh the cons.

In this chapter, some basic guidelines have been outlined for inexperienced authors. Although there is no magic formula for guaranteed publication, finding a mentor, learning to persevere in the face of rejection, and never ceasing to believe in addiction science are key elements to the process.

Please visit the website of the International Society of Addiction Journal Editors (ISAJE) at www.isaje.net to access supplementary materials related to this chapter. Materials include additional reading, exercises, examples, PowerPoint presentations, videos, and e-learning lessons.

\section{Notes}

${ }^{1}$ For the general purposes of streamlining and efficiency, the term faculty member or faculty (as an adjective) is used throughout this chapter to represent any kind of higher education advisor, supervisor, teacher, or researcher who might otherwise be called a researcher, a lecturer (junior or senior), a professor, etc. It should be noted that, depending on the country and/or institution, different terminology may be used.

${ }^{2}$ Let us not forget that this is the true purpose of scientific publishing!

${ }^{3}$ For students at some institutions, the dissertation articles must be published before the dissertation can be approved, and publication must therefore be prepared at an earlier stage.

${ }^{4}$ See http://core.ecu.edu/psyc/wuenschk/Help/ThesisDiss/thauth.htm

${ }^{5}$ And of course, those faculty members are usually getting paid as wellpublication is an expected part of the job.

${ }^{6}$ Including all of the authors of this chapter!

\section{References}

American Psychological Association. (2010, June 1). Ethical principles of psychologists and code of conduct: Including 2010 amendments. Retrieved from http://www.apa.org/ethics/code/index.aspx.

Azar, B. (2006, March). Publishing your dissertation. gradPSYCH Magazine. Retrieved from http://www.apa.org/gradpsych/2006/03/dissertation.aspx.

Beall, J. (2012). Predatory publishers are corrupting open access. Nature, 489(7415), 179. DOI: https://doi.org/10.1038/489179a

Beall, J. (2015, January 2). Beall's list of predatory publishers 2015. Retrieved from http://scholarlyoa.com/2015/01/02/bealls-list-of-predatory-publishers-2015/. 
Cham, J. (2005, March 13). The author list: Giving credit where credit is due. Piled Higher \& Deeper: A Grad Student Comic Strip. Retrieved from http:// phdcomics.com/comics.php?f=562.

Cornell, E., Doshi, R., Noel, J., \& Rusch, L. (2014). Authorship rights of graduate students. Unpublished guideline prepared for the Department of Community Medicine and Health Care, University of Connecticut School of Medicine, Farmington, CT.

Edwards, G. (Ed.). (2002). Addiction: Evolution of a specialist field. Oxford, England: Blackwell Publishing.

Farmington Consensus. (1997). Addiction, 92, 1617-1618.

Fine, M. A., \& Kurdek, L. A. (1993). Reflections on determining authorship credit and authorship order on faculty-student collaborations. American Psychologist, 48, 1141-1147.

Global Forum for Health Research. (2004). The 10/90 report on health research 2003-2004. Geneva, Switzerland: Author. Retrieved from http:// announcementsfiles.cohred.org/gfhr_pub/assoc/s14789e/s14789e.pdf.

Hagen, N. T. (2010). Deconstructing doctoral dissertations: How many papers does it take to make a $\mathrm{PhD}$ ? Scientometrics, 85, 567-579.

Gross, D., Alhusen, J., \& Jennings, B. M. (2012). Authorship ethics with the dissertation manuscript option. Research in Nursing \& Health, 35, 431-434.

Harvard Medical School Office for Research Issues. (1999, December 17). Authorship guidelines. Retrieved from http://hms.harvard.edu/abouthms/integrity-academic-medicine/hms-policy/faculty-policies-integrityscience/authorship-guidelines.

Humeniuk, R., Ali, R., Babor, T., Souza-Formigoni, M. L. O., de Lacerda, R. B., Ling, W, McRee, B., Newcombe, D., Hemraj, P., Poznyak, V., Simon, S., \& Vendetti, J. (2012). A randomized controlled trial of a brief intervention for illicit drugs linked to the Alcohol, Smoking and Substance Involvement Screening Test (ASSIST) in clients recruited from primary health-care settings in four countries. Addiction, 107, 957-966.

Large, M., Nielssen, O., Farooq, S., \& Glozier, N. (2010). Increasing rates of psychiatric publication from low- and middle-income countries. International Journal of Social Psychiatry, 56, 497-506.

Miller, P. M. (2011). Introducing the ISAJE-PARINT Online Mentoring Scheme. Journal of Groups in Addiction \& Recovery, 6, 272.

Morisano, D. (2013). Goal setting in the academic arena. In E. A. Locke \& G. Latham (Eds.), New developments in goal setting and task performance (pp. 495-506). New York, NY: Routledge.

Rehm, J., Baliunas, D., Borges, G. L. G., Graham, K., Irving, H., Kehoe, T., Parry, C. D., Patra, J., Popova, S., Poznyak, V., Roerecke, M., Room, R., Samokhvalov, A. V., \& Taylor, B. (2010). The relation between different dimensions of alcohol consumption and burden of disease-an overview. Addiction, 105, 817-843. 
Resta, R. G., Veach, P. M., Charles, S., Vogel, K., Blase, T., \& Palmer, C. G. (2010). Publishing a Master's thesis: A guide for novice authors. Journal of Genetic Counseling, 19, 217-227.

Robinson, S., \& Dracup, K. (2008). Innovative options for the doctoral dissertation in nursing. Nursing Outlook, 56, 174-178.

Rudestam, K. E., \& Newton, R. R. (1992). Surviving your dissertation: A comprehensive guide to content and process. Newbury Park, CA: Sage.

Saunders, J. B., Aasland, O. G., Babor, T. F., de la Fuente, J. R., \& Grant, M. (1993). Development of the Alcohol Use Disorders Identification Test (AUDIT): WHO collaborative project on early detection of persons with harmful alcohol consumption--II. Addiction, 88, 791-804.

Shore, B. M. (2014). The graduate advisor handbook: A student-centered approach. Chicago, IL: The University of Chicago Press. DOI: https://doi. org/10.7208/chicago/9780226011783.001.0001

Trammell, A. (2014, October 14). The benefits of publishing as an undergraduate. Retrieved from https://publish.illinois.edu/ugresearch/2014/10/14/thebenefits-of-publishing-as-an-undergraduate/.

University of Alberta Faculty of Graduate Studies and Research Council. (1996, November 15). Intellectual property policies: Guidelines for authorship. Retrieved from https:/uofa.ualberta.ca/graduate-studies/about/graduateprogram-manual/section-10-intellectual-property/10-2-guidelines-forauthorship.

University of Cambridge. (2014, November). Good research practice guidelines (Section 9): Dissemination and publication of results. Retrieved from http:// www.research-integrity.admin.cam.ac.uk/sites/www.research-integrity. admin.cam.ac.uk/files/good_research_practice_guidelines_11.14.pdf.

University of Pennsylvania's Office of the Provost. (2013, February 15). Fairness of authorship credit in collaborative faculty-student publications for $\mathrm{PhD}$, $A M$, and MS students. Retrieved from https://provost.upenn.edu/policies/ pennbook/2013/02/15/fairness-of-authorship-credit-in-collaborativefaculty-student-publications-for-phd-am-and-ms-students.

University of Toronto. (2007). Intellectual property guidelines for graduate students \& supervisors. Retrieved from http://www.sgs.utoronto.ca/currentstudents/ Pages/Intellectual-Property-Guidelines.aspx.

Warner, K. E., Tam, J., \& Koltun, S. M. (2014). Growth of Tobacco Control publications by authors from low- and middle-income countries. Tobacco Control, 23, 231-237.

Washington University in St. Louis. (2014, November 21). Policy for authorship on scientific and scholarly publications. Retrieved from https://wustl. edu/about/compliance-policies/intellectual-property-research-policies/ scientific-scholarly-authorship/.

Wuensch, K. (2008, November 30). Thesis authorship. Retrieved from http:// core.ecu.edu/psyc/wuenschk/Help/ThesisDiss/thauth.htm. 


\title{
Appendix A. Example of a Research Advisor-advisee Contract (Excerpted from Shore, 2014) $^{\mathrm{a}}$
}

\author{
Mutual Expectations Regarding Research Advising \\ High Ability and Inquiry Research Group \\ Department of Educational and Counselling Psychology, \\ McGill University
}

These notes are designed as guidelines to facilitate positive and mutually beneficial student-advisor relationships and to avoid problems on matters such as authorship and credits on publications, the extent of participation in activities other than the Thesis, Research Project, or Special Activity, and future access to data collected in the course of our work together. Some of the activities described below may be conducted in groups. Where these notes hinder rather than help, they should be amended to meet mutually acceptable needs, in general or as occasions arise.

\section{A. Advisor's Responsibilities}

1. Meet regularly with students and be contactable at other times.

2. Arrange substitute advising during extended absences.

3. Advise on course selection.

4. Assist in the preparation for comprehensive or oral examinations.

5. Help prepare conference and journal presentations based on work done in the program and assist with applications for support to attend suitable conferences at a reasonable distance and on whose programs students earn a place.

6. Help apply for funds to cover direct research costs and to provide stipends to full-time students.

7. Provide feedback within a mutually agreed time-frame on written work submitted for review.

\section{B. Students' Responsibilities}

1. Regularly pursue work and keep the advisor informed of progress or problems.

2. To a mutually agreed degree that respects other responsibilities and priorities, contribute to advancing team activities that further the common good of all of us working together-e.g., workshops for teachers, parent contacts, library orders, data bases, maintaining bibliographies and mailing lists, convening meetings, maintaining computers and supplies. These tasks will be equitably distributed.

3. Join in the preparation of conference presentations and publications on research and other activities done with faculty members. 
4. With appropriate guidance, prepare a draft version of the thesis or major report, normally within 3 months of its final presentation for master's degrees, or 6 months for doctoral degrees; after that point the advisor may take over such preparation and the order of authorship may be changed (within CPA, APA and McGill authorship guidelines).

5. Apply for scholarships and bursaries, especially FQRSC, McGill, and SSHRC (where eligible) [this list of funding sources should be amended to match local availability].

6. Participate to a mutually agreed extent in teaching-related activities such as the TA course.

7. Take a professional role in one's discipline by undertaking at least one student or regular membership in an appropriate professional or academic organization.

8. Keep at McGill a copy of raw data, coding sheets, instruments, and subject-identification data.

9. Upon graduation, leave with the advisor a printed copy of the main research report, and an electronic copy in modifiable form (e.g., not PDF) of any data and the text of the thesis or project.

10. Use Microsoft Word and APA [or other, as appropriate] style for written submissions.

11. Report annually in writing on progress and contributions (department and university forms).

12. Regularly attend and participate in research-team meetings.

C. Joint Responsibilities

1. Give full credit for the contributions of others and to research funding in all products.

2. Assign authorship according to the latest APA publication guidelines. (For example, if a thesis topic or report is entirely the student's original contribution, then the advisor's contribution is due a footnote. Shared scientific responsibility calls for co-authorship, with the student as first author on the main points of the student's research of those for which the student took primary creative responsibility, and the advisor as first author on any specific subpoints which the advisor contributed or a broader study of which the student is part.)

3. Both have unlimited access to the data collected on or about the topic of a thesis or project during the time worked together, plus any other that may be agreed to, giving due credit to its origin either by footnote or reference to previous publications.

D. Degree Covered by this Agreement

Check-mark all that apply [and revise this list as needed for your institution]:

$\square$ PhD Thesis or Dissertation

$\square$ MA Thesis

MA Research Project 
$\square$ MEd "Special Activity" Project

$\square$ Undergraduate Honors Thesis

$\square$ Independent Graduate Student Project

$\square$ Independent Undergraduate Student Project

$\square$ Other (specify):

$\square$ Not for formal credit

E. Comments, Additions, or Special Notes [expand this space as required]

F. Signatures

We agree to work together in an advisory relationship in accord with the above guidelines.

Advisor Date Student Date

Printed Name

Printed Name

One copy for each.

Note:

a This sample contract was also reproduced in: Shore, B. M. (2014). The graduate advisor handbook: A student-centered approach. Chicago, IL: The University of Chicago Press (in the series Chicago Guides to Academic Life). DOI: https:// doi.org/10.7208/chicago/9780226011783.001.0001

\section{Appendix B. Authorship Rights of Graduate Students ${ }^{\mathrm{b}}$}

\section{It is agreed that. . .}

1. Graduate students are a vulnerable population with regard to authorship issues in scientific publications because of their junior status in the academic hierarchy.

2. Graduate students rely on principal investigators, faculty members, and other individuals in positions of power for funding and for access to research opportunities and data.

3. Graduate students rely on principal investigators, faculty members, and other individuals in positions of power for successful completion of any graduate program.

4. Graduate students who participate in research studies often fulfill necessary roles and provide vital support toward the completion of research projects conducted by teams of faculty, students, and staff. 
5. Principal investigators, faculty members, and other individuals in positions of power can influence, directly or indirectly, positively or negatively, the credit given for work done by students following the successful completion of a research study.

6. Authorship credits are often important for graduate students' careers.

7. Students may be given inappropriate and unethical authorship credits to enhance the student's chances of success. Conversely, students may be denied appropriate and ethical authorship credit.

8. There is little recourse for a graduate student should a principal investigator, faculty member, or other individual in a position of power negatively influence deserved authorship credit.

9. A set of rights and guidelines to protect graduate students and to define faculty-student authorship criteria are needed.

10. The rights and guidelines listed in the sections "General Research Studies" and "Dissertation or Thesis Research" listed below shall be adopted to protect graduate students from negligence or mistreatment and to define graduate student authorship.

\section{General Research Studies}

1. A graduate student who has participated in a research study conducted by a faculty member who is affiliated with graduate student's program or who supervises the graduate student has the right to be invited to become an author on any report, abstract, journal manuscript, or other document developed based on the results of the study, provided the student has completed sufficient training.

a. Study participation may include, but is not limited to, the following: recruitment of study subjects, providing an intervention, data collection, data entry, questionnaire coding, supervision and training of study personnel, writing of the research protocol, or the provision of other technical services.

b. Authorship is defined as providing a major contribution to a report, abstract, journal manuscript, or other document including, but not limited to, the following: writing the final version of the submission, designing the study, interpreting the results, study coordination, statistical analysis, laboratory analysis, data management, or providing informative advice on study design and analysis.

c. Sufficient training may include, but is not limited to, the following: completion of specific coursework, knowledge of the subject matter, or knowledge of the study design. The extent of training is to be agreed upon prior to the student's involvement in the research study and occurs between the student, the study's principal investigator, and/or the student's major advisor. 
2. A graduate student's role in the drafting of a report, abstract, journal manuscript, or other document, as well as possible authorship position, is to be discussed prior to the first draft of a report, abstract, or journal manuscript.

3. Financial compensation, whether through graduate assistantships or by other means, is not a replacement for authorship credit.

4. Acknowledgement is not a replacement for authorship credit.

5. A graduate student's role on a report, abstract, journal manuscript, or other document shall not change without notifying the student, allowing the student to respond to the notification, and agreement of all co-authors.

6. A graduate student has the right to refuse authorship on a report, abstract, journal manuscript, or other document for any reason.

7. If a disagreement over authorship occurs between a graduate student and a principal investigator, the graduate student may appeal to the Director of their graduate program or the Chair of the department with which the principal investigator is affiliated to appoint an unbiased arbitration committee to resolve the conflict. This committee will be comprised of three individuals and will consist of at least one student.

8. The principal investigator or any other faculty member shall not penalize a graduate student by eliminating future authorship opportunities, removing study responsibilities, assigning an excessive workload, withholding monetary compensation, or imposing any other punishment, directly or indirectly, should the student disagree with the principal investigator over authorship or invoke independent arbitration.

9. These guidelines shall apply for an agreed upon amount of time after the student graduates, changes institutions, or otherwise is no longer affiliated with the graduate program. The time limit shall be agreed upon by the student, the study's principal investigator, and/or the student's major advisor.

\section{Dissertation or Thesis Research}

1. Research and analyses conducted by a graduate student for the purposes of fulfilling doctoral dissertation or master's-thesis requirements is considered the property of the graduate student, regardless of who is listed as principal investigator on funding, regulatory documentation, or other documentation.

2. A graduate student has the right to first authorship on any report, abstract, journal manuscript, or other document that is created based on the results of dissertation or thesis research conducted by said graduate student.

3. The principal investigator listed on funding, regulatory documentation, or other documentation that supports a graduate student's dissertation 
or thesis research shall in no way impede, and will support, said graduate student in creating a report, abstract, journal manuscript, or other document.

4. Data generated from dissertation or thesis research will revert to the principal investigator if, and only if, a graduate student has not produced a first draft of a report, abstract, journal manuscript, or other document within a previously agreed upon time window.

a. If no window is agreed upon, then the data generated from dissertation or thesis research shall not revert to the principal investigator under any circumstances.

b. If the first draft of a report, abstract, journal manuscript, or other document is not produced by the student within the previously agreed upon time window, the principal investigator must include the graduate student in the drafting of a report, abstract, journal manuscript, or other document using the guidelines specified in the "General Research Studies" section, unless the graduate student agrees to be excluded from the process.

5. A graduate student has a right not to publish, and not to have published, dissertation or thesis research.

a. A graduate student may invoke this right at any time prior to, during, or after the previously agreed upon publication window, unless the previously agreed upon window has already been exceeded, the graduate student has been included in the authorship process, and the results have already been published in a peer-review journal; or the graduate student has previously agreed to be excluded from the process.

6. If a disagreement over authorship occurs between a graduate student and a principal investigator, the graduate student may appeal to the Director of their graduate program or the Chair of the department with which the principal investigator is affiliated to appoint an unbiased arbitration committee to resolve the conflict. This committee will be comprised of three individuals and will consist of at least one student.

7. The principal investigator or any other faculty member shall not penalize a graduate student by eliminating future authorship opportunities, removing study responsibilities, assigning excessive workload, withholding monetary compensation, or by imposing any other punishment, directly or indirectly, should the student disagree with the principal investigator over authorship or invoke independent arbitration.

Note:

${ }^{b}$ This guideline was developed by Erin Cornell, Riddhi Doshi, Jonathan Noel, and Lisa Rusch in April 2014, when they were graduate students at the University of Connecticut in the Graduate Program in Public Health. 